\title{
Comparing the Scientific Quality Achieved by Funding Instruments for Single Grant Holders and for Collaborative Networks within a Research System: Some Observations
}

Link to publication record in Manchester Research Explorer

Citation for published version (APA):

Rigby, J. (2007). Comparing the Scientific Quality Achieved by Funding Instruments for Single Grant Holders and for Collaborative Networks within a Research System: Some Observations.

\section{Citing this paper}

Please note that where the full-text provided on Manchester Research Explorer is the Author Accepted Manuscript or Proof version this may differ from the final Published version. If citing, it is advised that you check and use the publisher's definitive version.

\section{General rights}

Copyright and moral rights for the publications made accessible in the Research Explorer are retained by the authors and/or other copyright owners and it is a condition of accessing publications that users recognise and abide by the legal requirements associated with these rights.

\section{Takedown policy}

If you believe that this document breaches copyright please refer to the University of Manchester's Takedown Procedures [http://man.ac.uk/04Y6Bo] or contact uml.scholarlycommunications@manchester.ac.uk providing relevant details, so we can investigate your claim.

\section{OPEN ACCESS}




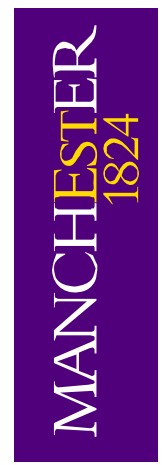

\section{Working Paper Series}

\section{Comparing the scientific quality achieved by funding instruments for single grant holders and for collaborative networks within a research system: some observations}

John Rigby

Manchester Business School Working Paper No 532

\section{Manchestier Business School}

Copyright (c) 2007, Rigby. All rights reserved.

Do not quote or cite without permission from the author.

Manchester Business School

The University of Manchester

Booth Street West

Manchester M15 6PB

+44(0)161306 1320

http://www.mbs.ac.uk/research/workingpapers/

ISSN 0954-7401

The working papers are produced by The University of Manchester - Manchester Business School and are to be circulated for discussion purposes only. Their contents should be considered to be preliminary. The papers are expected to be published in due course, in a revised form and should not be quoted without the authors' permission. 


\title{
Author(s) and affiliation
}

\author{
John Rigby \\ Manchester Institute of Innovation Research \\ Manchester Business School \\ University of Manchester \\ Harold Hankins Building \\ Manchester \\ UK \\ M13 9PL \\ E-Mail: john.rigby@manchester.ac.uk
}

\begin{abstract}
Increasingly, funding of academic research is carried out through the support of collaboration, rather than through single awards to a sole grant holder. The practice is well supported by evidence that larger, network-based research achieve high quality while leading to a number of capacity building benefits for the research system, although with significant transaction costs. However, the question of what kind of funding schemes should be made available to researchers is not a simple dichotomy between single grantholder projects and networks. A key question is how to achieve a balance in each subject field between different forms of funding instrument employed while ensuring different forms of funding retain a reputation for generating research of high scientific quality. This paper reports the results of a systematic comparison of the scientific quality of 1010 ISI scientific papers produced under two contrasting forms of funding instrument for a single year in the Austrian science system. Comparison of the arcsinh transformed citation counts of papers from the two main forms of funding for basic science at the level of main scientific field shows there is no statistically significant difference in the quality achieved by the two forms of funding. This may suggest that funders and research performers have deliberately ensured that different research instruments nevertheless achieve very similar levels of scientific excellence.
\end{abstract}

\section{Keywords}

research; funding mechanisms; collaboration; impact; arcsinh transformation

\section{How to quote or cite this document}

Rigby, John (2007). Comparing the Scientific Quality Achieved by Funding Instruments for Single Grant Holders and for Collaborative Networks within a Research System: Some Observations. Manchester Business School Working Paper, Number 532, available: http://www.mbs.ac.uk/research/workingpapers/ 
Comparing the scientific quality achieved by funding instruments for single grant holders and for collaborative networks within a research system: some observations.

Manchester Institute of Innovation Research Working Paper Series

Paper No. 12

J. Rigby, MIoIR, University of Manchester, Oxford Road, Manchester, M13 9PL

Corresponding Author: John.Rigby@manchester.ac.uk 
Increasingly, funding of academic research is carried out through the support of collaboration, rather than through single awards to a sole grant holder. The practice is well supported by evidence that larger, network-based research achieve high quality while leading to a number of capacity building benefits for the research system, although with significant transaction costs. However, the question of what kind of funding schemes should be made available to researchers is not a simple dichotomy between single grant-holder projects and networks. A key question is how to achieve a balance in each subject field between different forms of funding instrument employed while ensuring different forms of funding retain a reputation for generating research of high scientific quality. This paper reports the results of a systematic comparison of the scientific quality of 1010 ISI scientific papers produced under two contrasting forms of funding instrument for a single year in the Austrian science system. Comparison of the arcsinh transformed citation counts of papers from the two main forms of funding for basic science at the level of main scientific field shows there is no statistically significant difference in the quality achieved by the two forms of funding. This may suggest that funders and research performers have deliberately ensured that different research instruments nevertheless achieve very similar levels of scientific excellence.

Keywords: research; funding mechanisms; collaboration; impact; arcsinh transformation 


\section{Introduction}

National and international funding bodies for science have over the last thirty years offered a range of support to research for universities, the most commonly used comprising grants allocated at both responsive and the thematic level, and which are provided at a variety of scales and over varying timescales. Increasingly, these grants have been given for research activities that involve collaboration and networking. With the announcement of plans and first funding of research under the European Research Council, the EU's pan-European Union funding agency for research, there is now a further and potentially significant institution arriving on the scene from which grants to pursue research will be available (Scientific Council of the ERC, 2006a; 2006b) although the early plans of the Council will not lead immediately to the large scale funding of collaborative research. This paper contributes to the debate about the importance of ensuring that public funds achieve scientific excellence at the country level (May, 1997). It deals specifically with the question of the appropriateness of funding instruments, a matter raised by Lee and Bozeman (2005), by enquiring into the question of whether single grants or collaborative funding are more likely to achieve scientific excellence. It does so at the level of the research system and addresses the important issues of governance in relation to size and agglomeration of research funding in institutional settings (Bonaccorsi and Daraio, 2005).

The paper begins by reviewing the increasing practice of collaboration and examining the arguments which are used to support it. An analysis is then outlined which provides a comparison between two forms of funding instrument. Empirical data from the comparison of two of the most important funding schemes in the Austrian Science system is then presented and analysed. Some observations and possible answers to the questions posed are then offered. 


\section{Review of Literature}

Research funding policy

Research councils' allocation of funding at national level is supplemented by, in the case of the research councils of Member States within Europe, a large number of pan European initiatives funding initiatives, some supported by the European Union while others are being supported by other groupings, such as those facilitated through the DACH Agreement between Austria, Germany and Switzerland. Research funders have gradually acquired new approaches to the allocation of grants and have increased the range of objectives for which funding can be sought by research performers. Funding allocations by research councils have generally been of the pure type where research performers have complete discretion in the nature of the enquiry they carry out with their funding allocation, subject to the peer review process for their research proposal. However, research councils have increasingly come to allocate their funding through thematic programmes in which some aspect of the research is assumed, such as the general research area, a general question or problematique, or an identified user of the research output.

Recent work on knowledge production and knowledge producers has drawn attention to changing and strengthening interrelationships between the various traditional categories of knowledge producers (Etzkowitz and Leydesdorff, 2000) and to convergence between producers and users of knowledge which, it has been argued, have produced new forms of knowledge (Gibbons et al, 1994). As greater resources have been allocated to thematic research and more focus has been placed on problem solving, collaboration has been seen as essential to success in order to put sufficient and relevant effort behind attempts to find solutions to scientific, technological and societal problems. The developments have led some to say that the "past three decades could be credibly termed the era of inter-institutional research collaboration” (Corley et al 2006, page 975). 
The physical sciences were the first to be transformed into a large scale, international and highly collaborative and competitive form some thirty years ago. A process of transformation has now begun to affect biological sciences (Welsh et al, 2006). The phenomenon of "Big Biology" now promises to reproduce, within scientific domain of biology, a set of arrangements that are already well known in the physical sciences, although there are significant differences in the precise form in which the changes are occurring in biology Welsh et al (2006).

While support for collaborative research has been seen in a positive light - a welcome development in the governance of science - others have perceived it a way of dealing with the problems of the steady state in science (Ziman, 1994). As Melin has recently noted, (Melin, 2000) "attempts to force researchers to communicate and collaborate in order to share the facilities and equipment and reduce the costs because of strained budgets" are now commonplace as pressures grow on the resources available to science.

\section{The potential of collaboration}

Early policy interest in the question of the size of the group in which research was carried out focussed upon the link between productivity and group size, without a strong interest in the phenomena of collaboration between academic researchers and the link with the scientific impact of their work (Meador et al, 1992; Golden \& Carstensen, 1992). Increasingly however, there has been a heightening of focus on collaboration, and effectiveness and its relation to research quality. Evidence has been produced that collaborators are more productive (Zuckerman, 1967; Price and Beaver, 1966; Lee and Bozeman, 2005) with many benefits identified and scoped (Katz and Martin, 1997; Welsh et al., 2006), while other research has begun to explore the quality control aspects of collaboration work (Rigby and Edler, 2005). The evidence about the processes of scientific enquiry has gradually led to a requirement 
placed by research funders on research performers to use the collaborative research mode in more and more instances.

As the research on collaboration has grown, the international dimension has been extensively studied and has been observed to be associated with greater citation impact, a finding identified by Narin and Whitlow (1990) and noted since then by various scholars. The existence of the so-called "fourth rule" of international collaboration - that international papers create a greater impact - and show it to be a real effect and not an artefact of selfcitation (Van Raan, 1998) support the earlier contention of the value of collaborative work. As research has progressed, there has been a clear realisation that collaboration, which can be seen as autonomous process of scientific enquiry (Melin, 2000) that is connected both with the process of creativity and with peer review of findings, should be assisted and supported (Adams et al. 2005), particularly in certain areas where there is thought to be potential for interaction at larger scales (Adams et al., 2005) and that this process of collaboration in new areas previously thought difficult can be made possible through the use of information and communication technologies (Welsh et al 2006).

The issue of institutional size has also been considered by a number of scholars with Stankiewicz (1979) and Kyvik (1995) offering evidence that larger academic departments are more likely to create more "intellectual synergy". Kyvik’s work (1995) shows a consensus amongst those academics he studied for increased departmental size, supporting the argument that collaborative research across institutions may be more effective. There is some evidence however that an optimum size for a research group exists, with the implication that collaboration can only take place with a critical mass, but then becomes too heavy to manage with consequences for quality. The issue of differences between scientific fields is also an important dimension: specific disciplinary or field based characteristics which are themselves determined by the key factors of task uncertainty and the mutual dependence of the scholars 
concerned (Whitley, 2000) significantly affect the way in which research is carried out and place limits upon collaboration despite the presence of structures to support the practice.

\section{Scope and contexts}

However, despite considerable research on collaboration, researchers have begun to note a lack of detailed understanding of the scope of collaborative research, of the levels at which it is appropriate and whether it should be at the top-level between institutions or between researchers and what form of management these organisations should have. Amongst senior researchers in some fields, there is opposition to networks because of the loss of control (Schatz, 2005). The study by Corley et al (Corley et al, 2006) has reviewed large scale, multisite, multi-user, and multi-disciplinary collaborations and attempts to identify unique and specific factors that are linked to success defined in terms of scientific quality. While collaboration is seen to be generally beneficial as a form for carrying out research, there are limitations both intrinsic and extrinsic upon collaboration as a form of scientific enquiry.

Intrinsic limitations come from the increasing effort required to cope with increasing intellectual and physical distance (Katz and Martin, 1997). Attempts to synthesize different forms of knowledge from different domains or sub-domains take time and resources. As Jeffrey (2003) has noted, the greater the intellectual distance, the more effort is needed in building common understanding and common language through which research can proceed. Such attempts to develop transdisciplinary discourse carry risks for those involved, including both funders and research performers. Often though, the risk is that no scientific output is generated is small as even if the research fails to develop in a truly transdisciplinary form, research findings of some kind will emerge, albeit in more conventional modes.

Recent work on the effects of team size (Adams et al 2005) provides evidence of the presence of limits to collaboration. While their research shows that that collaboration is indeed a 
growing feature of the science system, the size of teams in which research is carried out is not growing so rapidly. Other significant studies of the details of the dynamics of collaboration have identified a range of difficulties in terms of the allocation of work, role definitions, risk, specialization, and a lack of initiative and willingness to engage (Hackett, 2005). Collaboration is here problematized as a contested space which leads to "negotiation and peer pressure to shape the research of new junior colleagues” (Hackett, 2005; page 800) leading to tension and disagreement. Collaboration for the sake of it or as "speculative venture", in which one attempts to engage with those that are likely to do one's career some good, is certainly not new in the world of science, but the scale at which it takes place may have grown in recent years with the growth of incentives to produce more, and the greater facilitation of collaborative work (Wagner, 2005; Schott, 1998; Whitley, 1984).

Geographical space has also been shown to exert a strong impact upon the potential of collaboration with increasing distance acting as a powerful barrier to attempts to work together. Coupled with the fact of physical distance, however, is the effect of country size, with smaller countries needing collaboration both internally and externally in order to facilitate access to complementary intellectual and physical assets. However, in Europe, where there is a mix of larger and smaller countries and physical distances are low, there is evidence that collaboration remains a national phenomenon rather than an international one (Frenken, 2002; Banchoff, T. 2002), despite the effect of nearly twenty years of funding of network projects at the European scale under the Framework Programmes of the European Union.

Extrinsic barriers to collaboration include political, economic and cultural differences that make it illegal or too costly for scientists to work together. However, increasingly large scale such barriers are loosing their impact because of political and scientific initiatives that create a variety of international, bi- / tri-and multilateral (e.g. the DACH agreement) bodies that support scientific collaboration. However, there has been concern that, for a variety of 
reasons, the design of schemes to promote collaboration within such schemes, and indeed in schemes run by a single science funding organisations at the national level, there is too much bureaucratic control. In relation to the biological sciences, Schatz (2003, 2004) has commented that network projects are becoming an instrument of controlling science rather than a means of facilitating it, while specifically at the EU level, Hakala et al (2002) have typified collaborative research funded under the Framework Programmes as restricting and inflexible. Attempts to discuss transdisciplinarity though draw attention away from the question of whether collaboration - the aggregation of research actors into teams and collectivities - is a sensible strategy within disciplinary or relatively narrow disciplinary work. Some of the limitations are arguments against collaboration per se but some are arguments against the ways in which collaboration has been pursued by scientists and or research councils and these problems relate to management and the application of rules. Many of these arguments against collaboration do not challenge the principle that collaboration is effective but undermine the rationale for it because of practical limitations concerned with implementation.

\section{A current research priority}

Resources for research are increasingly allocated to research collaborations and a plethora of schemes is on offer. It is no surprise given this growth of interest and the profusion of empirical data then that there has been a growth of interest in the effectiveness of such funding with scholars questioning whether collaboration is appropriate in a particular case (Dundar \& Lewis, 1998; Lee \& Bozeman, 2005) and whether there are performative effects on the collaboration behaviour of scientists with implications for quality. The approach taken here is that an appropriate method of investigating the effectiveness of collaboration is to consider the funding of collaborative research within the context of a specific research system. This is because the quality of the outputs of different research instruments is in part the result of a management and negotiation process that may seek to ensure a balance between more and less collaborative modes. 


\section{Methodology}

\section{The aim of the study}

The aim of this research is to investigate, within the context of a specific science funding system, whether differences in terms of funding mechanisms affect the scientific excellence of the research which they produce. In particular, the attempt is made to discern whether there is a difference in the scientific quality between the research carried out by smaller groups of scientists on the one hand and by research collaborations on the other. The methodology employed is that of comparison using two forms of research funding instrument, one instrument being grants to a single grant holder, the other instrument being to support a collaborative network of researchers, with the comparisons taking place between and within main scientific fields. To address the issue of quality, a causal model is proposed that posits type of funding and scientific field as predictor variables, and level of quality as the dependent variable.

\section{Establishing indicators of quality based on citation count}

The measures of quality used here are based on the citations received by the paper subject to a suitable transformation to the normal distribution for analysis. The extent of citation is commonly acknowledged to be an effective means of assessing the impact of a publication and the research associated with it and here the citation count of each paper is used as the measure of its quality. While uncited papers are generally regarded as having made less impact upon the scientific community that those which are cited, although some papers, socalled "sleeping beauties” (Van Raan, 2004) can remain unnoticed for a substantial period before making an impact, other highly cited papers may achieve their impact because they contain scientific error. In the research carried out here, a citation window of 5 years has been used, in order to ensure that significant number of citations has accumulated for each 
paper and that the longer term of the impacts of the papers that have been produced can be recognized. It is the case that generally, interdisciplinary research is more likely to show a delay in acquiring citations. This is a difficult area to investigate and the issue of the extent of interdisciplinarity within the papers examined has been ignored in this study.

In order to test the relationships between the different variables using a nested ANOVA and one-way ANOVA designs, a transformation of the citation counts of the papers as the measure of quality was carried out. As the data contain a number of zero counts, there was a need to employ a suitable transformation for the data in order to subsequently employ analysis of variance. Initially two transformations of the citation count data were reviewed for the data as recommended in the literature, firstly adding one to the zero counts and taking the log (Elliott, 1977) and the use of the arcsinh transformation. The use of transformations for citation and bibliographic data is a contentious issue as a number of scholars have noted, see Milligan in relation to the arcsinh (Milligan, 1987) and more recently Leydesdorff and Bensman (Leydesdorff and Bensman, 2006) who have noted the importance of using original untransformed data where a number of processes underlie the data under examination.

Nevertheless, analysis of variance has been used to test for effects between instruments and fields and, as the use of this technique requires data with more homogenous variance characteristics, a transformation has been carried out. It has been noted by some that ANOVA is often sufficiently robust to departures from the normal distribution, however (Quenouille, 1953). Furthermore, as others have pointed out, interpretation of the analysis on the transformed statistics can be carried out (Sheffe, 1959) and working back to the original data through a reversal of the transformation can be accomplished. In the case of the arcsinh though, this transformation employs the cosh function and generates median values, rather than means. In the case of the data under consideration here, the arcsinh transformation generated a distribution with a lower level of kurtosis and skewness than the logarithm 
transformed count of the $1+$ count of citations and this transformation was therefore used in the analysis of variance.

The papers

The data used for this comparison comprises the entire set of papers published during 2001 for the all research funded by the Austrian Science Fund under its research projects and its research networks. The citation data for each paper was obtained from Thomson Scientific's Web of Science, which includes the Science Citation Index ${ }^{\circledR}$, the Social Sciences Citation Index ${ }^{\circledR}$, the Arts \& Humanities Citation Index ${ }^{\circledR}$ the Index Chemicus ${ }^{\circledR}$ and the Current Chemical Reactions ${ }^{\circledR}$. The citation data comprised, for each paper produced, the number of citations for the period 2001 until 2005 inclusive. For each paper, the citation ratio was also provided, indicating the relative quality of the paper in the journal in which it was published. For all papers, the scientific field in which the paper appeared was obtained. In all, 1010 papers were identified, although it should be noted that some of the projects and some of the networks produced papers that were not published in journals indexed by the ISI.

\section{Defining the case - the limits of explanation}

In order to reduce the effect of cultural factors, the enquiry which has been carried out and which is reported here has used data from a single science system, which is that of Austria. Austria is therefore defined as the case or context in which any statistical inferences will be valid. The Austrian case provides a valuable and suitable example with which to examine the difference between single grant and more collaborative schemes because research funding to scientists for basic research takes place through a single research council. The presence of two different institutional arrangements for the support of research makes possible a comparison of output between these two forms of research at the level of citation impact of the papers produced. The research does not imply that the inferences drawn should be extrapolated to other science systems, although it may be the case that they are subsequently found to be capable of so being. 


\section{The funding instruments}

In the assessment of quality, the predictor variable, which is that of funding instrument, is dichotomous, being either project or network. However, it can be the case that some papers result from collaboration between projects and networks. The issue then arises as to how to attribute papers of this kind ${ }^{1}$. The step which has been taken here is to remove any such ambiguous papers from the data set, rather than classifying them as both, or as collaborative, which clearly in a sense they are.

In Austria, the two major forms of funding to basic science are offered by the research council and application for funding is highly competitive. This is particularly the case as the peer review process for the applications for grants is international, as is the quality control mechanism for the mid-term and final evaluations of the projects themselves. The major share of the funding allocated by the Science Fund is to the Einzelprojekten / Forschungsprojekte, or the research projects. These receive around $70 \%$ of the total funding of the Science Fund. The network funding receives around $20 \%$ of the budget of the Science Fund. This money is allocated to the Forschungsschwerpunkte (FSP) and the Spezialforschungsbereiche (SFB). The Science Fund allocates its other funding to a number of smaller projects. During the last decade, the number of network projects has slightly fallen although it then increased right at the end of the period.

Both forms of funding are well established in the Austrian science system and have been used extensively. Scientists who use these forms of funding are using funding instruments that have been in existence for over 30 years, the research projects being instituted in 1966, while the research networks were begun in 1972 in the form of the FSP. The development of

\footnotetext{
${ }^{1}$ Such a paper, by virtue of being an instance of collaboration between research funded as collaborative and research funded under a single grant would have to be classified as collaborative.
} 
research networking in Austria has followed developments in Germany and in Switzerland, whose networking activities were established slightly earlier.

Research network funding in Austria is provided for two main forms of networking activity. The two forms of networks differ principally in terms of the extent to which they seek to achieve interdisciplinary and transdisciplinary research. The FSP are slightly less ambitious in this respect, providing funds for 6 years while SFBs provide funds for 10 years to reflect these different expectations. Though the two types of network funding seek to achieve inter- and transdisciplinary research, they tend to comprise a number of sub-projects, numbering up to 20. These sub-projects are not however free standing research activities but are linked thematically to each other, supporting the aims of the entire work of the collaboration.

\section{Scientific fields}

The papers used in the analysis were allocated to 25 scientific fields on the basis of their appearance in the 172 Thomson ISI journal categories. These papers were then allocated via the mapping noted below to four main scientific fields created for the purpose of the analysis. These four fields comprise Physical Sciences and Engineering, Life Sciences, Health Sciences and Social Sciences. This variable for Main Field of Science was then used in the analysis of quality.

Table 1 about here:

\section{Analysis of Quality}

The analysis of quality sought to review the data set of papers and to assess the difference in publication output quality by field and instrument through a nested ANOVA. This model assumed an initial allocation of papers to instrument and thereafter to different academic fields. The following figure identifies the model.

Figure 1 about here: 
The purpose of the nested ANOVA is to assess differences in absolute quality between funding instruments within fields and between different fields. Post hoc tests of differences between fields can be carried out to provide appropriate probability levels for the multiple comparisons between combinations of instrument and main field.

\title{
Results
}

Detailed analysis - results of tests on research quality

The initial test of research quality employed a nested ANOVA with categorical variables of main field (MAIN_FIELD\$ (4 levels: 1, 2, 3, 4) and instrument (INSTRUMENT\$ (2 levels: 1, 2). The dependent variable was the arcsinh of the citation count of papers produced.

\author{
Main Field \\ MAIN_FIELD\$ Physical Sciences and Engineering Value = 1 \\ MAIN_FIELD\$ Life Sciences Value $=2$ \\ MAIN_FIELD\$ Health Sciences Value $=3$ \\ MAIN_FIELD\$ Social Sciences Value $=4$ \\ Instrument \\ INSTRUMENT\$ Project Value $=1$ \\ $($ INSTRUMENT\$ Network Value $=2$
}

Table 2 about here:

Table 3 about here:

Table 4 about here:

Figure 2 about here:

Table 5 about here: 
Table 6 about here:

Table 7 about here:

\section{Commentary on tests of means}

The tests of means show that the variable MAIN_FIELD\$ is significant in the analysis of variance and explains the differences between the mean citation counts per publication $[\mathrm{p}=0.000]$. The table shown above gives the HSD probabilities of where means of certain combinations of instrument and main field are significantly different from each other, and where they are not. For ease of viewing, those instrument and main field combinations which are significantly different are underlined. It can be seen by reading the probabilities in this table that in any of the four main fields, the mean number of citations between projects and networks does not vary significantly [Row 1: Column 5 ( $\mathrm{p}=1.00)$; Row 2: Column 6 ( $\mathrm{p}=0.98)$; Row 3: Column 7 ( $\mathrm{p}=1.00)$; Row 4: Column $8(\mathrm{p}=0.96)$ ]. There is no significant difference between projects and networks therefore in the overall level of quality they produce at the level of the mean citation count. These differences can be read onto the figure of differences in means, Figure 2, which does not display confidence intervals based on Tukey Honestly Significant Differences.

\section{Discussion}

\section{Aims of the Study}

This study has investigated differences in the scientific quality between four main fields of research and within fields and between research instruments. While the study has used data on publication outputs, no implications on the productivity of instruments or main fields is made as these differences in the occurrence of papers by funding instrument may be related to funding about which we have no information. In any case, it is not the aim of the research to examine the link between funding, but rather to concentrate upon the issue of quality and its relationship with the type of funding instrument employed to carry out this research. 


\section{Differences between research instruments}

The observations which can be made about quality are of a number of kinds: they concern differences between instruments and between fields. The differences between funding instruments in terms of quality show that so far as quality is concerned and when measured by the transformed citation counts, projects and networks within a major scientific field achieve very similar levels of quality. That this is the case across a range of scientific disciplines that vary in many ways in terms of their task uncertainty and mutual dependence is an important finding. That this should be so suggests that network funding as it is implemented here in the case of Austria is successful in achieving a level of quality that is equivalent to the level which is achieved by the more traditional, single grant funding.

It may be appropriate therefore to reject the claim that networks support inferior research. Furthermore, the broader claim that in any one scientific area, research council funding should change the emphasis of its support to another form of funding, i.e. from projects to networks or from networks to projects, cannot be made on the basis of the data presented here. The argument that "big biology" now requires Life, and to a lesser degree Health Sciences to direct greater resources towards network funding cannot be easily substantiated, on the basis of the analysis carried out, at least within the context of the national science system examined as neither networks nor single grant funding is significantly more likely to produce higher quality research.

The degree to which quality levels are equal between the two funding instruments within each field requires explanation. It is perhaps the case that sufficient time has elapsed, in Austria at least, for researchers and funders to create a set of funding arrangements that are equally successful in achieving scientific goals of excellence across scientific instruments. It may also 
be the case that over time, the funding allocation to projects and networks has been monitored to ensure that, within fields, the two forms of funding instrument - projects and networks generally perform equally, thereby protecting the reputation of each scheme. This study has not sought to obtain data that could be used to establish if such monitoring and feedback activities have taken place.

The fact of equal quality between instruments within a field raises the question of whether networks should be achieving more in terms of higher levels of quality, given their setup and other costs and whether, if they only achieve the same level of quality, they are in effect less efficient forms of research. While this research can give insight into aspects of this question, the issue of input cost has been deliberately ignored as the focus has been upon the achievement of scientific excellence and reputation of respective research instruments. Furthermore, it may be contended that the outputs of the projects and the networks are not comparable, in that they are of different types. To some degree, this is a valid objection to part of the work undertaken here; however, the focus of the work has been on quality of output measured through the use of citation counts, rather than on the type of output, so the objection may be discounted to some degree.

\section{Differences between main fields}

The analysis which has been carried out here has established that main scientific fields vary in the essential parameters of their productivity, when measured by an analysis of variation of the citation counts of the papers produced within them, and that these differences are constant regardless of the funding instrument employed to produce papers.

Two fields of the four main fields that are similar in terms of scientific activities and practice do however behave in a similar way and are not separable in the statistical sense that their mean differences are negligible. These two fields are Life Sciences and Health Sciences. Physical Sciences and Engineering and Social Sciences individually form two further and 
separate areas, with Physical Sciences and Engineering having a slightly lower mean citation count (both amongst projects and networks) than the Life and Health Sciences Group, while the Social Sciences have a lower mean citation count still than the Physical Sciences and Engineering. The data support the view that main fields may constitute a coherent set of practices and routines that, while not time invariant, are likely to remain constant over long periods.

\section{Conclusions}

The conclusions presented here are based on one year's publications in ISI journals from projects and networks that are funded by the Austrian Science Fund. These networks and projects absorb the largest share of all funding, taking just under $90 \%$ of the resources allocated to research by the Science Fund in 2002. While changes in policy can make major changes to the operation of a system, the amount of significant change taking place within the period of time from which these publications are counted is likely to be relatively low. Hence it is important that the publications are counted from one year in order to give a reliable picture of the actual differences that may arise between different forms of funding instrument. The use of a long citation window from 2001 to 2005 of five years is a suitably long period for publications generated under the networks to obtain a significantly large number of citations that would facilitate reliable estimates, in each paper's case, of a scientific impact. However, it may be argued that the process of citation could itself be subject to variable effects over a longer period, as scientists' and policy makers’ approaches to research change. It is hoped in this case that the influence is small and that any changes in culture that subsequently affect the process by which citations arise are negligible.

From the point of view of research funding organisations, it is clear that great care is advisable to ensure quality of its major instruments, particularly when both instruments are 
funding basic scientific research and are at different times funding competitive and complementary forms of research. In biosciences, as in life sciences, there is no evidence that the balance of funding between research instruments should change. In the physical sciences and engineering however, there is evidence that more network funding might be appropriate. However, the basis of this conclusion is, as noted above, the data from one year's publications, although the citation counts and citation ratio which constitute the assessment of quality are from a five year period.

The data show strong evidence of a balance between different forms of funding in terms of the incidence of excellence. Such a balance is likely to arise from the professional and effective management of the funding allocation by the Science Fund and by appropriate use of the funds themselves by the scientists who carry out the research. Who precisely is involved in attempts to manage this process - to balance the two different forms of funding and how the process operates are very much open questions.

This study has not set out to argue for or against one form of funding or another but to examine the critical issue of how resources should be allocated between different forms of research practice. In the case examined here, this allocation is between single grant holder project funding and more collaborative research that is carried out in networks. Funding modes are often best approached from the point of view of scientists themselves, but the issue of how best to match funds to the form in which the research takes place, and the appropriateness of one form of funding over another, are key decisions at many levels for researchers and for funders. If, on the basis of the comparative data from other science systems, it became clear that one form of funding was significantly more likely to generate higher quality papers or significantly more likely to produce poorer quality papers, there would indeed be evidence for a change in the way in which funds were allocated. 
Finally, the evidence that the biosciences should move, within the context of Austria, to the funding of larger scale networks, eschewing research projects and pooling resources, including personnel, on the model of the physical sciences and engineering, appears not to be justified on the basis of the data considered here.

\section{References}

ADAMS J.D., BLACK, G.C., CLEMMONS, J.R., STEPHAN, P.E. (2005) Scientific teams and institutional collaborations: Evidence from US universities, 1981-1999, Research Policy, 34 : 259.285.

BANCHOFF, T. (2002) Institutions, inertia and European Union Research Policy, Journal of Common Market Studies, $40: 1.21$.

BONACCORSI A., \& DARAIO, C. (2005) Exploring size and agglomeration effects on public research productivity, Scientometrics, $63: 87.120$.

CORLEY, E.A., BOARDMAN, P.C. \& BOZEMAN. B. (2006) Design and the management of multiinstitutional research collaborations: Theoretical implications from two case studies, Research Policy, 35 : 975.993.

DUNDAR, H., \& LEWIS D.R. (1998) Determinants of research productivity in higher education, Research In Higher Education, 39 : 607.631.

ELLIOTT, Elliott, J.M. (1977). Some methods for the statistical analysis of samples of benthic invertebrates (2nd ed.). Freshwater Biological Association Scientific Publication : 25 Freshwater Biological Association, Ambleside, England.

FRENKEN, K. (2002) A New Indicator of European Integration and an Application to Collaboration in Scientific Research, Economic Systems Research, 14 : 345.361.

GIBBONS, M., LIMOGES, C., NOWOTNY, H. SCHWARTZMAN, S., SCOTT, P. \& TROW, M. (1994). The new production of knowledge. The dynamics of science and research in contemporary societies. Sage, London.

GOLDEN, J., \& CARSTENSEN, F. V. (1992) Academic research, productivity, department size and organization: further results, rejoinder Economics of Education Review 11 : 169.171. 
HACKETT, E. (2005) Essential Tensions: Identity, Control, and Risk in Research Social Studies of Science, $35: 787.826$.

HAKALA, J., KUTINLAHTI , P., \& KAUKONEN, E. (2002) Becoming International, becoming European: EU Research Collaboration at Finnish Universities The European Journal of Social Science Research, 15 : 357.379 .

JEFFREY, P. (2003) Smoothing the waters: observations on the process of cross-disciplinary research collaboration. Social Studies of Science 25 : 539.562.

KATZ, J.S., MARTIN, B.R. (1997) What is research collaboration? Research Policy 26 : 1:18.

KYVIK, S. (1995) Are big university departments better than small ones? Higher Education 30: 295.304.

LEE, S. \& BOZEMAN, B. (2005) The impact of Research Collaboration on Scientific Productivity, Social Studies of Science, $35: 673.702$.

LEYDESDORFF, L. AND BENSMAN, S. (2006) Classification and Power laws: The Logarithmic Transformation Journal Of The American Society For Information Science And Technology, $57: 1470-1486$.

MAY, R.M. (1997) The Scientific Wealth of Nations, Science 275 : 793.796.

MELIN, G. (2000) Pragmatism and Self-organisation: Research Collaboration on the Individual Level, Research Policy, $29: 31.40$.

MILLIGAN, G.W. (1987) The use of the Arc-Sine Transformation in Analysis of Variance, Educational and Psychological Measurement 47 : 563.573.

NARIN, F., \& WHITLOW, E. S. (1990) Measurement of scientific cooperation and co-authorship in EC-related areas of science. Luxemburg: Office for Official Publications of the European Communities. EC-Report EUR 12900.

PRICE, D. DE SOLLA, \& BEAVER, D.D. (1966) Collaboration in an Invisible College, American Psychologist, $21: 1011.1018$.

QUENOUILLE, M.H. (1953) The Design and Analysis of Experiments, Griffin, London.

RIGBY, J. \& EDLER, J.E. (2005) Peering inside research networks: Some observations on the effect of the intensity of collaboration on the variability of research quality Research Policy, 34 : 784.74.

SCHATZ, G. (2003) Networks, fretworks FEBS LETTERS 553 : 1.2. 
SCIENTIFIC COUNCIL OF THE EUROPEAN RESEARCH COUNCIL (2006 a) European Research Council - Work Programme 2007 Draft Version, 13 October 2006.

SCIENTIFIC COUNCIL OF THE EUROPEAN RESEARCH COUNCIL (2006 b) The ERC Launch Strategy.

SHEFFE, H. (1959) The analysis of Variance, John Wiley, London.

STANKIEWICZ, R. (1979). 'The size and age of Swedish academic research groups and their scientific performance', in Andrews, F.M. (ed.). Scientific Productivity. The Effectiveness of Research Groups in Six Countries. Cambridge/Paris, Cambridge University Press/UNESCO.

VAN RAAN, A.F.J. (1998) The influence of international collaboration On the impact of research results Some simple mathematical considerations concerning The role of self-citations Scientometrics, 42 : 423.428.

VAN RAAN, A.F.J. (2004) Sleeping Beauties in science Scientometrics, 59 : 467.472.

WELSH, E., JIROTKA, M., AND GAVAGHAN, D. (2006) Post-genomic science: cross-disciplinary and large-scale collaborative research and its organizational and technological challenges for the scientific research process, Philosophical Transactions Of The Royal Society AMathematical Physical And Engineering Sciences 364 : 1533.1549.

WHITLEY, R. (200) The Intellectual and Social Organisation of the Sciences, Oxford: Oxford University Press, $2^{\text {nd }}$ Edition.

ZIMAN, J. M. (1994) Prometheus Bound: Science in a Dynamic Steady State, Cambridge University Press, Cambridge.

ZUCKERMAN, H. (1967) Nobel Laureates I Science: Patterns of Productivity, Collaboration and Authorship, American Sociological Review, 32 : 391.403.

\section{Acknowledgements}

I would like to thank Professor A.F.J. Van Raan, Dr Keith Julian, and Professor Michel Callon for their helpful comments. 
Figures

Figure 1. Model of Nested ANOVA for Testing Role of Factors

\begin{tabular}{|c|c|c|c|c|c|c|c|}
\hline \multicolumn{4}{|c|}{ Instrument 1} & \multicolumn{4}{|c|}{ Instrument 2} \\
\hline 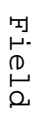 & 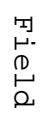 & 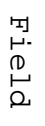 & $\begin{array}{l}\stackrel{T}{\vec{D}} \text {. } \\
\stackrel{D}{\circ}\end{array}$ & $\begin{array}{l}\stackrel{T}{~} . \\
\stackrel{0}{0} \\
\stackrel{2}{2}\end{array}$ & $\begin{array}{l}\text {. } \\
\stackrel{D}{0} \\
\stackrel{2}{2}\end{array}$ & 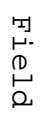 & 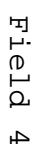 \\
\hline$\mapsto$ & N & $\omega$ & 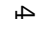 & $\mapsto$ & $N$ & $\omega$ & \\
\hline
\end{tabular}

Figure 2. Differences in Mean by Instrument and Main Field

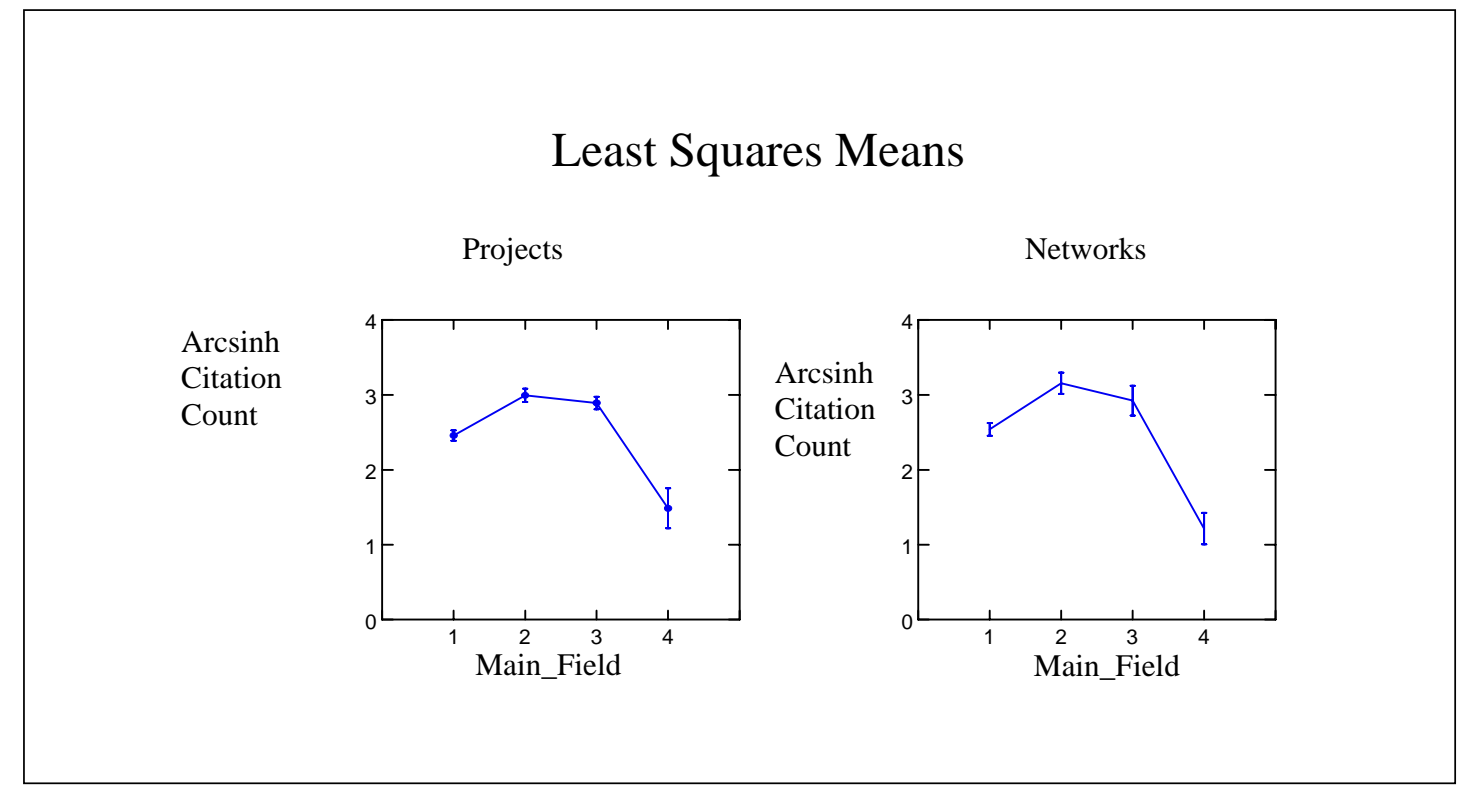

Post hoc tests

Durbin-Watson D Statistic 1.321

First Order Autocorrelation 0.336 
Tables

Table 1. Scientific Field and Main Field of Science Mapping - Including Number of Papers.

\begin{tabular}{|c|c|c|c|c|c|}
\hline \multirow[b]{2}{*}{ Basic Field of Science } & \multicolumn{4}{|c|}{ Main Field of Science (number of papers) } & \multirow[b]{2}{*}{$\begin{array}{c}\text { Total } \\
\text { Papers }\end{array}$} \\
\hline & $\begin{array}{l}\text { Sciences and } \\
\text { Engineering }\end{array}$ & $\begin{array}{c}\text { Life } \\
\text { Sciences }\end{array}$ & $\begin{array}{c}\text { Health } \\
\text { Sciences }\end{array}$ & $\begin{array}{c}\text { Social } \\
\text { Sciences }\end{array}$ & \\
\hline Agriculture and Foods & 1 & 9 & 0 & 0 & 10 \\
\hline Astronomy and Astrophysics & 23 & 0 & 0 & 0 & 23 \\
\hline Behavioural Sciences & 0 & 0 & 0 & 5 & 5 \\
\hline Biochemistry & 0 & 113 & 0 & 0 & 113 \\
\hline Biology & 0 & 53 & 0 & 0 & 53 \\
\hline Biomedical Sciences & 0 & 0 & 30 & 0 & 30 \\
\hline Chemistry & 96 & 0 & 0 & 0 & 96 \\
\hline Computer Applications & 0 & 0 & 0 & 28 & 28 \\
\hline Earth Sciences & 21 & 0 & 0 & 0 & 21 \\
\hline Electronics & 5 & 0 & 0 & 0 & 5 \\
\hline Engineering & 5 & 0 & 0 & 0 & 5 \\
\hline Environmental Science & 0 & 17 & 0 & 0 & 17 \\
\hline Genetics & 0 & 36 & 0 & 0 & 36 \\
\hline Instrumentation & 5 & 0 & 0 & 0 & 5 \\
\hline Management & 0 & 0 & 0 & 5 & 5 \\
\hline Materials Science & 44 & 0 & 0 & 0 & 44 \\
\hline Mathematics & 45 & 0 & 0 & 0 & 45 \\
\hline Medicine & 0 & 0 & 178 & 0 & 178 \\
\hline Meteorology & 4 & 0 & 0 & 0 & 4 \\
\hline Microbiology & 0 & 6 & 0 & 0 & 6 \\
\hline Nuclear Science & 4 & 0 & 0 & 0 & 4 \\
\hline Pharmacology & 0 & 0 & 29 & 0 & 29 \\
\hline Physics & 229 & 0 & 0 & 0 & 229 \\
\hline Veterinary Medicine & 0 & 0 & 2 & 0 & 2 \\
\hline Zoology & 0 & 17 & 0 & 0 & 17 \\
\hline Total & 482 & 251 & 239 & 38 & 1010 \\
\hline
\end{tabular}

Table 2. Nested ANOVA of Main Field and Instrument for Arcsinh of Citation Count

Nested ANOVA of Main Field\$, Instrument and the Arcsinh of the Citation Count

N: 1010; Multiple R: 0.291; Squared multiple R: 0.084

\begin{tabular}{l|l|l} 
CONSTANT & & 2.458
\end{tabular}

MAIN_FIELD\$ 1

\begin{tabular}{l|l|l} 
INSTRUMENT\$ & 1 & 0.000
\end{tabular}

MAIN_FIELD\$ 2

\begin{tabular}{l|l|l} 
INSTRUMENT\$ & 1 & 0.537
\end{tabular}

MAIN_FIELD\$ 3

INSTRUMENT\$ 110.435

MAIN_FIELD\$ 1

\begin{tabular}{l|l|l} 
INSTRUMENT\$ & 2 & 0.081
\end{tabular}

MAIN_FIELD\$ 2

\begin{tabular}{l|l|l} 
INSTRUMENT\$ & 2 & 0.697
\end{tabular}

MAIN_FIELD\$ 3

\begin{tabular}{l|l|l} 
INSTRUMENT\$ & 2 & 0.466
\end{tabular} 
Table 3. Analysis of Variance Table: Effect of Main Field

\begin{tabular}{|l|l|l|l|l|l|}
\hline \multicolumn{5}{|l|}{ Analysis of Variance } \\
\hline Source & Sum-of-Squares & $\mathrm{df}$ & Mean-Square & F- ratio & P \\
MAIN_FIELD\$ & 136.438 & 6 & 22.740 & 15.408 & 0.000 \\
Error & 1480.290 & 1003 & 1.476 & & \\
\hline
\end{tabular}

Table 4. Differences between Means

\begin{tabular}{|lllll|}
\hline \multicolumn{5}{|l|}{ Differences Between Means } \\
Main & Instrument & LS & SE & N \\
Field & & Mean & & \\
1 & 1 & 2.458 & 0.071 & 288 \\
2 & 1 & 2.995 & 0.088 & 184 \\
3 & 1 & 2.893 & 0.083 & 208 \\
4 & 1 & 1.487 & 0.267 & 11 \\
1 & 2 & 2.539 & 0.086 & 194 \\
2 & 2 & 3.155 & 0.143 & 67 \\
3 & 2 & 2.924 & 0.199 & 31 \\
4 & 2 & 1.214 & 0.210 & 27 \\
\hline
\end{tabular}

Table 5. Row Designation for Pairwise Mean Differences

\begin{tabular}{|lll|}
\hline ROW & MAIN_FIELD\$ & INSTRUMENT\$ \\
1 & 1 & 1 \\
2 & 2 & 1 \\
3 & 3 & 1 \\
4 & 4 & 1 \\
5 & 1 & 2 \\
6 & 2 & 2 \\
7 & 3 & 2 \\
8 & 4 & 2 \\
\hline
\end{tabular}

Table 6. Matrix of Pairwise Mean Differences

\begin{tabular}{|ccccccccc|}
\hline \multicolumn{8}{c|}{ Matrix of Pairwise Mean Differences: Using model MSE of 1.476 with 1003 df. } \\
$\begin{array}{c}\text { Row / } \\
\text { Column }\end{array}$ & 1 & 2 & 3 & 4 & 5 & 6 & 7 & 8 \\
1 & 0 & & & & & & & \\
2 & 0.54 & 0 & & & & & & \\
3 & 0.44 & -0.1 & 0 & & & & & \\
4 & -0.97 & -1.51 & -1.41 & 0 & & & & \\
5 & 0.08 & -0.46 & -0.35 & 1.05 & 0 & & & \\
6 & 0.7 & 0.16 & 0.26 & 1.67 & 0.62 & 0 & & \\
7 & 0.47 & -0.07 & 0.03 & 1.44 & 0.38 & -0.23 & 0 & \\
8 & -1.24 & -1.78 & -1.68 & -0.27 & -1.33 & -1.94 & -1.71 & 0 \\
\hline
\end{tabular}


Table 7. Matrix of Pairwise Comparisons: Tukey HSD - Probabilities

\begin{tabular}{|c|c|c|c|c|c|c|c|c|}
\hline \multicolumn{9}{|c|}{$\begin{array}{l}\text { Post Hoc Test: Tukey HSD Multip } \\
\text { probabilities } \\
\text { (Significant values are underlined) }\end{array}$} \\
\hline Row/ & 1 & 2 & 3 & 4 & 5 & 6 & 7 & 8 \\
\hline 1 & 1.00 & & & & & & & \\
\hline 2 & $\underline{0.00}$ & 1.00 & & & & & & \\
\hline 3 & $\underline{0.00}$ & 0.99 & 1.00 & & & & & \\
\hline 4 & $\underline{0.02}$ & $\underline{0.00}$ & $\underline{0.00}$ & 1.00 & & & & \\
\hline 5 & 1.00 & $\underline{0.00}$ & 0.06 & $\underline{0.00}$ & 1.00 & & & \\
\hline 6 & $\underline{0.00}$ & 0.98 & 0.74 & $\underline{0.00}$ & $\underline{0.01}$ & 1.00 & & \\
\hline 7 & 0.32 & 1.00 & 1.00 & $\underline{0.00}$ & 0.67 & 0.99 & 1.00 & \\
\hline 8 & $\underline{0.00}$ & $\underline{0.00}$ & $\underline{0.00}$ & 0.96 & $\underline{0.00}$ & $\underline{0.00}$ & $\underline{0.00}$ & 1.00 \\
\hline
\end{tabular}

